\title{
Phthalate exposure in Thai children and adolescents
}

\author{
Nuttanun Sedtasiriphokin', Vichit Supornsilchai ${ }^{2,},{ }^{,},{ }^{1}$ Chutima Jantarat ${ }^{3}$, Wichit Nosoongnoen ${ }^{4}$
}

Abstract

Background: Phthalates are found in products made of plastic. Because of concerns regarding the hazards of phthalate exposure, including endocrine disruption, many countries have regulations to restrict their use in products used by children. However, in Thailand, no such restrictions exist, and data relating to phthalate exposure are scarce.

Objectives: To determine the level of exposure of Thai children and adolescents to phthalates, and study its associations with sociodemographic data and the exposure to potential sources of phthalates.

Methods: Healthy children aged 2-18 y were enrolled into the present cross-sectional study between January 2016 and December 2016 inclusive. Their anthropometric indices and Tanner staging were determined. Urinary concentrations of the phthalate metabolites, monomethyl phthalate (MMP) and mono- $n$-butyl phthalate (MBP), were determined in spot samples by high-performance liquid chromatography to estimate the level of phthalate exposure. Associations between sociodemographic data, exposure to potential sources of phthalates, and phthalate metabolite concentrations were analyzed. Results: We included 103 boys and 118 girls with a mean age of $9.4 \pm 3.64$ (range 2.8-17.1) y and detected MMP in $28.5 \%$ and MBP in $88.6 \%$. The geometric means (interquartile range) of urinary MMP and MBP were 3400 (2489, 4642) and $214.4(164,279) \mu \mathrm{g} / \mathrm{g}$ creatinine (Cr), respectively. Significant associations were found between exposure to floor cleaning products and Cr-adjusted urinary MMP level $(P<0.05)$, and paint and Cr-adjusted urinary MMP and MBP levels $(P<0.05)$. Prepuberty was significantly associated with urinary Cr-adjusted MMP level.

Conclusion: Urinary phthalate metabolite levels were high in a proportion of Thai children and adolescents. Exposure to floor cleaning products and paint is associated with phthalate exposure, and advanced Tanner stage is negatively associated with urinary Cr-adjusted MBP.

Keywords: MBP, MMP, monomethyl phthalate, mono-n-butyl phthalate, phthalate, Thai children and adolescents

Endocrine disrupting chemicals are synthetic compounds that can interfere with endocrine and reproductive systems, and they are commonly found in products used in everyday life [1]. These chemicals are used in the manufacture of a wide variety of industrial and common household products. Phthalates - or benzene-1,2-dicarboxylic acid and its esters, such as diisooctyl esters - are used as plasticizers to increase flexibility, stability, and durability, and they are commonly

*Correspondence to: Vichit Supornsilchai, Division of Endocrinology, Department of Paediatrics, King Chulalongkorn Memorial Hospital, Bangkok 10330, Thailand, e-mail: vichit.s@chula.ac.th 'Department of Paediatrics, Faculty of Medicine, Chulalongkorn University, Bangkok 10330, Thailand 2Division of Endocrinology, Department of Paediatrics, Faculty of Medicine, Chulalongkorn University, Bangkok 10330, Thailand ${ }^{3}$ School of Pharmacy, Walailak University, Nakhon Si Thammarat 80161, Thailand ${ }^{4}$ Department of Pharmacy, Faculty of Pharmacy, Mahidol University, Bangkok 10400, Thailand (c) (1) () ( 2017 Nuttanun Sedtasiriphokin, Vichit Supornsilchai, Chutima Jantarat, Wichit Nosoongnoen This Work is licensed under Creative Common License 
used ingredients in plastic manufacturing. Phthalates can be found in plastic products, such as children's toys, child care products, cosmetics, personal care products, medical devices, food packaging, poly(vinyl chloride) (PVC) plastics, building materials, and automotive components [2]. Low-molecularweight phthalates, including di- $n$-butyl phthalate (DBP), dimethyl phthalate (DMP), and diethyl phthalate, are used in adhesives, detergents, and solvents - any or all of which can be found in cosmetics and skincare products. High-molecularweight phthalates, such as di(2-ethylhexyl) phthalate and benzylbutyl phthalate, are used to increase the flexibility of plastic and can be found in products, such as toys, bags, gloves, and medical equipment [3]. Exposure to these chemicals can occur via ingestion, inhalation, or dermal contact [4-8].

Low-molecular-weight phthalates are metabolized in various ways: diester phthalates are hydrolyzed by esterases and lipases in the intestine to their respective monoester phthalates and excreted in urine and feces. High-molecularweight phthalates are further metabolized from monoesters via hydroxylation or oxidation to produce a number of oxidative metabolites that are then excreted in urine within $24 \mathrm{~h}$ of exposure. Furthermore, oxidative metabolites can conjugate to form hydrophilic glucuronide conjugates, which are also excreted in urine $[9,10]$. Therefore, measurement of urinary phthalate metabolites is the best way to determine the level of phthalate exposure. The biomarkers for exposure to DMP and DBP are monomethyl phthalate (MMP) and mono- $n$-butyl phthalate (MBP), respectively. Several studies have been conducted on the long-term health effects of phthalates, including abnormalities of the male reproductive system (cryptorchidism and hypospadias) [11-14], precocious puberty [15], obesity [16], lower intelligence quotient [17], autism spectrum disorder [18, 19], attentiondeficit/hyperactivity disorder $[9,20]$, gender confusion in male children born to mothers with high urinary phthalate level during pregnancy [21], asthma [22-24], allergic rash in children [25-27], and increased prevalence of premature labor $[28,29]$.

For these reasons, many countries now have a heightened level of concern about the hazards of exposure to phthalates, especially in children. Because children are considered vulnerable persons, laws that prohibit the use of phthalates in toys and products intended for children have been enacted. Such laws came into effect in the European Union in 2005, in the USA in 2008, and in Canada in 2011; however, no such restrictions have been put in place in Thailand. Moreover, data relating to phthalate exposure among children and adolescents in Thailand are scarce.

Accordingly, the aim of the present study was to investigate the level of phthalate exposure in Thai children and adolescents by determining phthalate metabolite levels in urine samples. A secondary aim was to study the associations between both sociodemographic data and exposure to potential sources of phthalates and urinary phthalate metabolite concentrations.

\section{Materials and methods}

\section{Subjects}

After our study protocol was approved by the Institutional Review Board (IRB) of the Faculty of Medicine, Chulalongkorn University, Bangkok, Thailand (IRB No. 538/58), we enrolled 231 healthy children aged $2-18$ y into the present cross-sectional study during the recruitment period from January 2016 to December 2016. The opportunity to join the study was promoted on a website that is supported by the Department of Paediatrics, Faculty of Medicine, Chulalongkorn University. Children with any of the following conditions were excluded: acute kidney injury, chronic kidney disease, inability to urinate voluntarily, or chronic illness. Only children with a fully completed questionnaire and a morning urine sample containing at least $50 \mathrm{~mL}$ of urine in a phthalatefree polypropylene tube were included. Seven children with an incomplete questionnaire and 3 children with inadequate amounts of urine were excluded. Patient data were collected on the date of urine collection and no follow-up visit was required. Written informed consent was obtained from the parent(s) or legal guardian(s) of each child, and assent was obtained from all children aged $\geq 8 \mathrm{y}$.

\section{Clinical examination}

Pubertal stage was assessed according to Marshall and Tanner criteria, which defines development of puberty by physical examination based on pubic hair growth, genitalia development in boys, and breast development in girls. Pubertal stage was determined in each child based on line drawings created by the parent(s). Tanner II genitalia in boys and Tanner II breasts in girls were regarded as pubertal onset. Weight was measured without shoes and in light clothing using a digital electronic scale, and height was measured using a stadiometer. Body mass index (BMI) was calculated as weight in kilograms divided by height in meters squared $\left(\mathrm{kg} / \mathrm{m}^{2}\right)$. Age- and gender-specific BMI $z$-scores were adjusted using World Health Organization BMI growth references. Overweight and obesity status was defined as BMI $z$-score greater than +1 standard deviation $(\mathrm{SD})$ and greater than $+2 \mathrm{SD}$, respectively. Waist 
circumference was measured in standing position at the midpoint between the lowest rib margin and the iliac crest after a gentle expiration. Child waist circumference was divided by height and hip circumference to calculate the waist-to-height and waist-to-hip ratio, respectively.

\section{Urine sample analysis}

A morning urine sample was collected from each child into a phthalate-free polypropylene tube on the day of examination at King Chulalongkorn Memorial Hospital. When the urine sample was received for analysis at the School of Pharmacy, Walailak University (Nakhon Si Thammarat, Thailand), a 5 $\mathrm{mL}$ aliquot was sent to determine creatinine $(\mathrm{Cr})$ level, and the remaining sample was stored at $-20^{\circ} \mathrm{C}$ until assay of the metabolites. Urine samples were analyzed for MMP and MBP using high-performance liquid chromatography (HPLC).

\section{Sample preparation for identification of phthalates in urine}

A standard stock solution for each analyte was prepared at $400 \mathrm{mg} / \mathrm{mL}$ acetonitrile and stored at $-20^{\circ} \mathrm{C}$ until use. Urine samples were stored in $15 \mathrm{~mL}$ centrifuge tubes at $-20^{\circ} \mathrm{C}$ until analysis and then thawed at $25^{\circ} \mathrm{C}$. An aliquot $(1 \mathrm{~mL})$ of urine was placed into a $10 \mathrm{~mL}$, glass vial, dried under a stream of nitrogen gas, and reconstituted with $100 \mathrm{~mL}$ of acetonitrileacetic acid $(99.9 / 0.1, \mathrm{v} / \mathrm{v})$. The resulting turbid solution was then centrifuged at 13,000 rpm for $5 \mathrm{~min}$, which resulted in sedimentation of the precipitate. The clear supernatant was then assayed using HPLC.

\section{Analysis of phthalates}

MMP and MBP were obtained from Sigma-Aldrich at purities of $>97.0 \%$. Chromatographic grade acetonitrile and acetic acid (glacial) were purchased from Merck. Millipore-Q ultrapure water $\left(18.20 \mathrm{~m} \Omega . \mathrm{cm}^{-1}, 25^{\circ} \mathrm{C}\right)$ was used to prepare all aqueous media (Merck Millipore). Chromatographic analysis was performed using an ultra-HPLC system (Dionex Ultimate 3000, Thermo Fisher Scientific). A stock standard solution for each analyte was prepared at $400 \mu \mathrm{g} / \mathrm{mL}$ in acetonitrile and stored at $-20^{\circ} \mathrm{C}$. Calibration standards were prepared by fortifying MMP and MBP in blank urine in the concentration range $0.1-10 \mu \mathrm{g} / \mathrm{mL}$. The standard solutions were then treated in the same manner as urine samples before analysis. Chromatographic data were acquired and processed using Chromeleon software (Thermo Fisher Scientific). A Sepex GP-C18 column $(1.8 \mu \mathrm{m}, 2.1 \mathrm{~mm}$ $\varnothing \times 100 \mathrm{~mm}$ ) was used for chromatographic separation of phthalates. The mobile phase consisted of acetonitrile-acetic acid $(99.9 / 0.1, \mathrm{v} / \mathrm{v})$ and water, which were designated as $\mathrm{A}$ and $\mathrm{B}$, respectively [30]. The gradient elution program was as follows: from 0 to $5 \mathrm{~min}, 30 \% \mathrm{~A}$; linear increase to $90 \%$ A, from 5 to $7 \mathrm{~min}$; linear decrease to $30 \% \mathrm{~A}$; and, stabilization at initial condition $(30 \% \mathrm{~A}, 70 \% \mathrm{~B})$ for $3 \mathrm{~min}$. The flow rate was $0.4 \mathrm{~mL} / \mathrm{min}$, the column temperature was maintained at $45^{\circ} \mathrm{C}$, and the detector wavelength was set at $228 \mathrm{~nm}$. This method was validated in terms of specificity, linearity, accuracy, and precision according to the guidelines of the International Council for Harmonisation of Technical Requirements for Pharmaceuticals for Human Use. The method was found to be specific because there was no interference between the analytes (MMP and MBP) and blank urine (Figure 1). Linearity of calibration standards in the range $0.1-10 \mu \mathrm{g} / \mathrm{mL}$ was observed, with a correlation coefficient higher than 0.99 . Accuracy and precision were determined at 3 concentration levels and found to be within validation criteria (recovery $100 \pm 15 \%$; relative standard deviation $\pm 15 \%$ ). SI-0236 Vortex-Genie 2 Mixer (Scientific Industries) and Mikro 200/200R centrifuge (Hettich) were used for solution mixing and centrifugation, respectively. An XSE Analytical Balance (Mettler-Toledo) was used for mass measurements.

Urinary $\mathrm{Cr}$ was analyzed by the enzymatic method using Vitros CREA Slides and Vitros chemistry products on a Vitros 350 Chemistry System (Ortho Clinical Diagnostics). Each urinary phthalate metabolite concentration (in nanograms per milliliter) was adjusted to micrograms per gram of $\mathrm{Cr}$.

\section{Questionnaires}

A questionnaire was designed to elicit sociodemographic information and phthalate exposure data about each child. Data that were collected included age, sex, current residence, caregiver level of education, family income, self-awareness or parental assessment of pubertal status, total daily hours of television viewing, exercise habits, eating habit risks (including consumption of junk food, canned food, and bottled milk), use of plastic containers for food and water, use of microwave oven to heat plastic food containers, and use of plastic toys. Frequency of exposure was classified into 6 categories, including "never", "at least once per month", "once per month", "once per week", "more than $2 \mathrm{~d}$ per week", and "at least once a day". Use of personal care products and exposure to other sources of phthalates (e.g., shampoo, soap, toothpaste, hair 


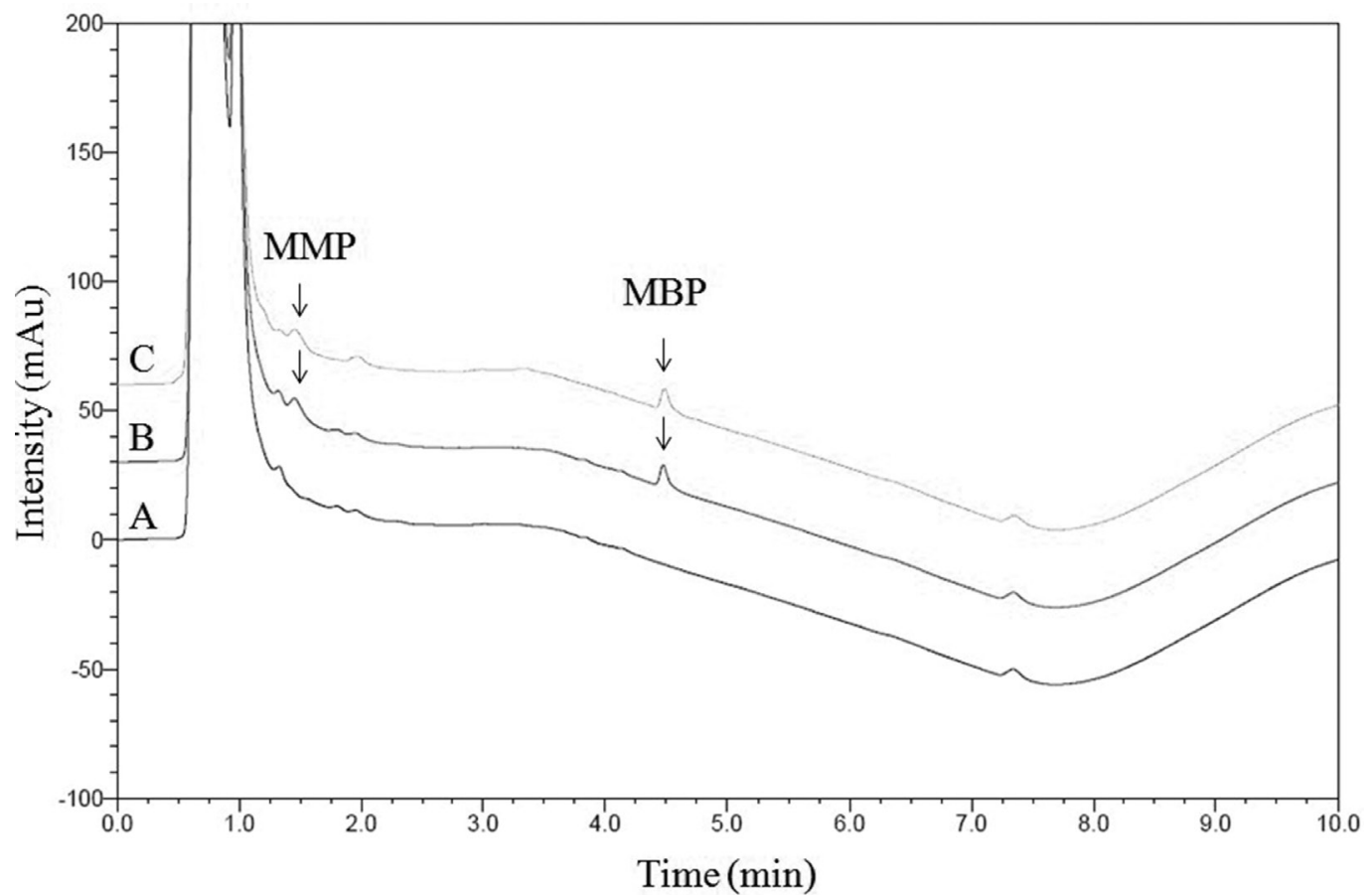

Figure 1. (A) Chromatogram of blank urine; (B) phthalate-spiked blank urine (MMP and MBP at $250 \mathrm{ng} / \mathrm{mL}$ ); and (C) representative urine sample containing MMP and MBP. MBP, mono-n-butyl phthalate; MMP, monomethyl phthalate

gel, lotions, floor cleaning liquid, and paints) were also collected and recorded. Exposure to these products was recorded as "Yes" or "No". Parents were also asked to recollect and report how many of these products their child was exposed to during the $24 \mathrm{~h}$ before urine collection for analysis of association with urinary phthalate metabolite concentrations.

\section{Statistical analysis}

Continuous data were reported as median (interquartile range [IQR], i.e., 25th, 75th percentiles) or mean \pm standard deviation (SD). Multiple linear regression analysis was used to identify the association between the level of urinary phthalate metabolites and Tanner stage adjusted by sex. An independent $t$ test was used to evaluate the association between urinary phthalate metabolite concentrations and potential sources of phthalate exposure. $P<0.05$ was considered to be significant. All statistical analyses were performed using IBM SPSS Statistics for Windows (version 21).

\section{Results}

We included data from both boys and girls, who had a mean age of $9.4 \pm 3.64$ (range $2.83-17.10$ ) y. Most children were aged 6-11 y (Table 1). Sociodemographic characteristics (Table 1) showed no significant associations with phthalate metabolites (data not shown). MMP was detected in about a third and MBP was detected in almost all urine specimens. The mean concentration of urinary MMP was 1303.94 $\mathrm{ng} / \mathrm{mL}$, and that of MBP was $563.82 \mathrm{ng} / \mathrm{mL}$. The median Cr-adjusted concentration of MMP was $0 \mu \mathrm{g} / \mathrm{g} \mathrm{Cr}$ and of MBP was $252 \mu \mathrm{g} / \mathrm{g}$ Cr (Table 2). In boys, the median (IQR) concentrations of adjusted MMP was $0(0,533) \mu \mathrm{g} / \mathrm{g} \mathrm{Cr}$ and MBP $211.4(75.9,426.8) \mu \mathrm{g} / \mathrm{g}$ Cr. In girls, the adjusted concentrations of MMP was $0(0,1054.4) \mu \mathrm{g} / \mathrm{g} \mathrm{Cr}$ and MBP was 193.8 (6.2, 579.1) $\mu \mathrm{g} / \mathrm{g} \mathrm{Cr}$.

No correlation was observed between urinary phthalate metabolites and age, gender, family income, parental education, secondhand smoke, media exposure times per day, BMI, waist circumference, waist-to-height ratio, or waist-tohip ratio (data not shown). Other variables, including canned food consumption, canned beverage consumption, use of plastic containers for food, bottled water, use of microwave to heat plastic food containers, junk food consumption, bottled milk consumption, and exposure to plastic toys, were also not found to be associated with urinary phthalate metabolite levels (data not shown).

Higher Tanner stage was significantly associated with lower urinary Cr-adjusted MBP levels (Table 3). Compared with children not exposed to either paints or floor cleaning 
Table 1. Sociodemographic characteristics of the study population $(\mathrm{N}=221)$

\begin{tabular}{lr}
\hline Characteristic & $\mathbf{n}(\%)$ \\
\hline Sex & \\
Male & $103(45.9)$ \\
Female & $118(54.0)$ \\
Age (y), mean \pm SD & $9.4 \pm 3.64$ \\
$<6$ & $44(19.9)$ \\
$6-11$ & $129(58.3)$ \\
$12-18$ & $48(21.7)$ \\
Family income (EUR/mo) & \\
$<€ 526$ & $45(20.4)$ \\
$€ 526-€ 1052$ & $68(30.7)$ \\
$>€ 1052$ & $108(48.8)$ \\
Education of parents & \\
None & $2(0.9)$ \\
Elementary & $26(11.7)$ \\
High school & $29(13.0)$ \\
Vocational certificate & $36(16.1)$ \\
Bachelor of Arts and higher & $128(57.9)$ \\
Pubertal staging & \\
Prepuberty & $130(58.8)$ \\
Puberty & $71(32.1)$ \\
Uncertain & $20(9.0)$ \\
Media exposure & \\
$<1 \mathrm{~h}$ & $35(15.8)$ \\
$1-2 \mathrm{~h}$ & $76(34.3)$ \\
$>2 \mathrm{~h}$ & $110(49.7)$ \\
\hline
\end{tabular}

Notes: EUR, euro; SD, standard deviation

Table 2. Detection rate of phthalate metabolites

\begin{tabular}{lrr}
\hline & MMP & MBP \\
\hline $\mathrm{n}(\%)$ & $63(28.5)$ & $196(88.6)$ \\
Mean $\pm \mathrm{SD}(\mu \mathrm{g} / \mathrm{g}$ of $\mathrm{Cr})$ & $1937.95 \pm 4754.27$ & $657.97 \pm 1459.75$ \\
$\mathrm{GM}(95 \% \mathrm{Cl})(\mu \mathrm{g} / \mathrm{g}$ of $\mathrm{Cr})$ & $3400(2489.9-4642.8)$ & $214.4(164.6-279.1)$ \\
Median $(\mu \mathrm{g} / \mathrm{g}$ of $\mathrm{Cr})$ & 0 & 252 \\
\hline
\end{tabular}

Notes: $\mathrm{Cl}$, confidence interval; $\mathrm{Cr}$, creatinine; GM; geometric mean; MBP, mono- $n$-butyl phthalate; MMP, monomethyl phthalate; SD, standard deviation liquids, urinary concentrations of MMP and MBP were significantly higher in children exposed to paints, and urinary concentrations of MMP were significantly higher in children exposed to floor cleaning liquid products (Table 4).

\section{Discussion}

To our knowledge, this is the first report in Thailand to study urinary phthalate metabolite levels in Thai children and adolescents. Exposure to phthalates may be associated with adverse health outcomes, especially in children. In the present study, we measured MMP and MBP, which are phthalate metabolites, and $\mathrm{Cr}$ levels in morning spot urine samples from Thai children and adolescents. The detection rates of MMP and MBP were 28.5\% and $88.6 \%$, with median concentrations of 0 and $252 \mu \mathrm{g} / \mathrm{g} \mathrm{Cr}$, respectively. When compared with other studies fromAsia(Table 5), we found a lower detection rate of MMP; we also noted a lower median concentration level of urinary Cr-adjusted MMP concentration, compared with a study from China ( 0 and $12.2 \mu \mathrm{g} / \mathrm{g}$ $\mathrm{Cr}$, respectively). For MBP, we found a lower detection rate, but a higher median urinary Cr-adjusted MBP level than found by the study from China ( 252 and $74 \mu \mathrm{g} / \mathrm{g}$ of $\mathrm{Cr}$, respectively) [31]. Median concentration of MBP from the present study was higher than concentrations reported from studies in Spain (252 and $30.2 \mu \mathrm{g} / \mathrm{g} \mathrm{Cr}$ ) [32] and the USA (252 and $19.8 \mu \mathrm{g} / \mathrm{g} \mathrm{Cr}$ ) [33] (Table 5). DBP, the parent compound of MBP, was restricted from children's products in the USA (Consumer Product Safety Improvement Act in 2008) and the European Union (EU) (Registration, Evaluation, Authorisation and Restriction of Chemicals 2005), and this may be the reason why urinary phthalate levels found by studies in the USA and Europe were lower for levels of MBP compared with those reported in our present study. Other factors that may be responsible for these differences include age and age-dependent metabolism, age group of participants, differences in food intake, variations in personal care product use patterns, and variations in levels of phthalates in food packaging and personal care products by country. Other sources of phthalates, such as medical products

Table 3. Beta coefficient of $\mathrm{Cr}$-adjusted urinary MMP and MBP concentrations ( $\mu \mathrm{g} / \mathrm{g}$ of $\mathrm{Cr}$ ) according to Tanner stage adjusted by sex

\begin{tabular}{|c|c|c|c|c|c|c|}
\hline \multirow[t]{2}{*}{ Characteristics } & \multicolumn{3}{|c|}{$\begin{array}{l}\text { Adjusted urinary MMP* } \\
\text { ( } \mu \mathrm{g} / \mathrm{g} \text { of Creatinine) }\end{array}$} & \multicolumn{3}{|c|}{$\begin{array}{l}\text { Adjusted urinary MBP* } \\
\text { ( } \mu \mathrm{g} / \mathrm{g} \text { of Creatinine) }\end{array}$} \\
\hline & Beta coefficient & SE & $P$ & Beta coefficient & SE & $P$ \\
\hline Tanner stage & -303.76 & 260.01 & 0.24 & -200.14 & 85.41 & 0.02 \\
\hline
\end{tabular}

Notes: The $P$-values were generated by multiple linear regression analysis. MBP, mono- $n$-butyl phthalate; MMP, monomethyl phthalate; $\mathrm{SE}$, standard error. *Adjusted by sex; $P<0.05$ indicates significance 
Table 4. Phthalate metabolite values expressed as mean $\pm \mathrm{SD}$ and median (IQR) ( $\mu \mathrm{g} / \mathrm{g}$ of Creatinine) by source of exposure

\begin{tabular}{|c|c|c|c|c|c|c|c|c|}
\hline \multirow{2}{*}{ Source of exposure } & & \multirow{2}{*}{$\mathbf{n}$} & \multicolumn{3}{|c|}{ MMP } & \multicolumn{3}{|c|}{ MBP } \\
\hline & & & Mean \pm SD & Median (IQR) & $P$ & Mean \pm SD & Median (IQR) & \\
\hline \multirow[t]{2}{*}{ Shampoo } & No & 39 & $1573.5 \pm 3705.8$ & $0(0,533)$ & 0.88 & $762.3 \pm 1567.1$ & $256.1(47.9,633.6)$ & 0.78 \\
\hline & Yes & 165 & $1701.2 \pm 4784.8$ & $0(0,459.8)$ & & $685.8 \pm 1530.6$ & $200.4(20.7,440.9)$ & \\
\hline \multirow[t]{2}{*}{ Hair conditioner } & No & 121 & $1616.6 \pm 4682.9$ & $0(0,528.9)$ & 0.82 & $633.2 \pm 1417.2$ & $238.4(47.9,522.2)$ & 0.45 \\
\hline & Yes & 83 & $1764.5 \pm 4478.1$ & $0(0,459.8)$ & & $798.4 \pm 1694.2$ & $160.4(7.3,548.4)$ & \\
\hline \multirow[t]{2}{*}{ Hair spray/hair gel } & No & 187 & $1774.8 \pm 4757.4$ & $0(0,619.9)$ & 0.31 & $743 \pm 1594.6$ & $212.1(18,540.3)$ & 0.19 \\
\hline & Yes & 17 & $598.3 \pm 1689.2$ & $0(0,0)$ & & $232.5 \pm 211.3$ & $196.1(91.6,281.5)$ & \\
\hline \multirow[t]{2}{*}{ Toothpaste } & No & 5 & $3688.8 \pm 4423.4$ & $1054.4(533,7238.1)$ & 0.32 & $693.4 \pm 761.1$ & $256.1(206,1063.3)$ & 0.99 \\
\hline & Yes & 199 & $1626.3 \pm 4593.6$ & $0(0,438.1)$ & & $700.6 \pm 1549.5$ & $206.9(18,523.6)$ & \\
\hline \multirow[t]{2}{*}{ Mouthwash } & No & 162 & $1639.8 \pm 4510.5$ & $0(0,533)$ & 0.82 & $681.3 \pm 1516.8$ & $212.8(61.9,523.6)$ & 0.73 \\
\hline & Yes & 42 & $1819.5 \pm 4939.8$ & $0(0,438.1)$ & & $774.1 \pm 1615.5$ & $177.6(0,579.1)$ & \\
\hline \multirow[t]{2}{*}{ Shaving cream } & No & 200 & $1710.3 \pm 4629.8$ & $0(0,531)$ & 0.46 & $712.2 \pm 1547$ & $212.8(25.3,529.2)$ & 0.44 \\
\hline & Yes & 4 & $0 \pm 0$ & $0(0,0)$ & & $110.4 \pm 83.9$ & $128.2(45.8,175)$ & \\
\hline \multirow[t]{2}{*}{ Perfume } & No & 182 & $1815.8 \pm 4822.9$ & $0(0,533)$ & 0.21 & $725.2 \pm 1584.6$ & $212.8(43.4,530.5)$ & 0.51 \\
\hline & Yes & 22 & $527.2 \pm 1276.9$ & $0(0,0)$ & & $495.6 \pm 1027.7$ & $153.8(9.1,336.2)$ & \\
\hline \multirow[t]{2}{*}{ Soap } & No & 8 & $3107.9 \pm 6036.6$ & $222.7(0,3849)$ & 0.37 & $649.8 \pm 1157.5$ & $37.9(0,896.4)$ & 0.92 \\
\hline & Yes & 196 & $1618.4 \pm 4531.9$ & $0(0,483.5)$ & & $702.5 \pm 1549.7$ & $210.7(45.7,522.9)$ & \\
\hline \multirow[t]{2}{*}{ Lotion } & No & 97 & $1313.6 \pm 3350.9$ & $0(0,43)$ & 0.28 & $703.9 \pm 1448.2$ & $209.3(61.9,559.9)$ & 0.98 \\
\hline & Yes & 107 & $2006.1 \pm 5472.6$ & $0(0,925.4)$ & & $697.3 \pm 1614.8$ & $200.4(9.1,440.9)$ & \\
\hline \multirow[t]{2}{*}{ Cosmetics } & No & 167 & $1669.3 \pm 4547$ & $0(0,533)$ & 0.96 & $657.1 \pm 1469.9$ & $212.1(47.9,522.2)$ & 0.39 \\
\hline & Yes & 37 & $1710.8 \pm 4844.4$ & $0(0,445.3)$ & & $895.8 \pm 1805.3$ & $200.4(6.2,694.9)$ & \\
\hline \multirow[t]{2}{*}{ Sunscreen } & No & 160 & $1706.1 \pm 4590.9$ & $0(0,772.7)$ & 0.90 & $691.6 \pm 1522.3$ & $216.5(58.6,529.2)$ & 0.84 \\
\hline & Yes & 43 & $1606.7 \pm 4687$ & $0(0,0)$ & & $746 \pm 1609.9$ & $196.1(2.9,514.2)$ & \\
\hline \multirow[t]{2}{*}{ Deodorant } & No & 148 & $1901.8 \pm 4825.5$ & $0(0,1015.9)$ & 0.26 & $726.7 \pm 1564.3$ & $226.2(70.3,554.2)$ & 0.69 \\
\hline & Yes & 56 & $1082.3 \pm 3877.1$ & $0(0,0)$ & & $630.8 \pm 1462.5$ & $153.2(5.9,316.6)$ & \\
\hline \multirow[t]{2}{*}{ Leather polish } & No & 194 & $1652 \pm 4499.4$ & $0(0,528.9)$ & 0.74 & $679.1 \pm 1501.9$ & $208.1(10.1,527.9)$ & 0.38 \\
\hline & Yes & 10 & $2157.3 \pm 6388.6$ & $0(0,204)$ & & $1114.5 \pm 2122.5$ & $217(100.3,418.4)$ & \\
\hline \multirow[t]{2}{*}{ Floor cleaning liquid } & No & 159 & $1258.8 \pm 2968.8$ & $0(0,528.9)$ & $0.014^{*}$ & $625 \pm 1386.9$ & $206.9(43.4,522.2)$ & 0.19 \\
\hline & Yes & 45 & $3153.9 \pm 7917.9$ & $0(0,382.1)$ & & $967.1 \pm 1963.8$ & $219.8(6.2,579.1)$ & \\
\hline \multirow[t]{2}{*}{ Washing powder } & No & 124 & $1213.5 \pm 2836.3$ & $0(0,494.4)$ & 0.07 & $629.7 \pm 1423.6$ & $206.2(8.2,479.5)$ & 0.41 \\
\hline & Yes & 80 & $2394.9 \pm 6384$ & $0(0,529)$ & & $810.1 \pm 1694.6$ & $242.8(70.3,674)$ & \\
\hline \multirow[t]{2}{*}{ Dish washing soap } & No & 96 & $1242.1 \pm 3027.9$ & $0(0,366.5)$ & 0.20 & $637.6 \pm 1445.6$ & $208.1(8.2,522.9)$ & 0.58 \\
\hline & Yes & 108 & $2063.2 \pm 5613.5$ & $0(0,496.4)$ & & $756.3 \pm 1613.3$ & $209(70.3,563.7)$ & \\
\hline \multirow[t]{2}{*}{ Vinyl products } & No & 133 & $1666.1 \pm 4582.4$ & $0(0,459.8)$ & 0.91 & $737.2 \pm 1598.1$ & $232.4(29.9,559.9)$ & 0.70 \\
\hline & Yes & 69 & $1746 \pm 4695.4$ & $0(0,533)$ & & $647.5 \pm 1432.1$ & $193.8(43.4,440.9)$ & \\
\hline \multirow[t]{2}{*}{ Paints } & No & 196 & $1512 \pm 3876.7$ & $0(0,452.6)$ & $0.011^{*}$ & $640.4 \pm 1389.1$ & $206.7(25.3,518.2)$ & $0.005^{*}$ \\
\hline & Yes & 8 & $5714.5 \pm 13151.4$ & $0(0,4023.9)$ & & $2170.1 \pm 3452.7$ & $436.2(63.6,3792.1)$ & \\
\hline \multirow[t]{2}{*}{ Insecticide } & No & 190 & $1521.5 \pm 4151.9$ & $0(0,459.8)$ & 0.08 & $656.8 \pm 1472.2$ & $206.2(20.7,523.6)$ & 0.14 \\
\hline & Yes & 14 & $3784.2 \pm 8558.2$ & $0(0,809.8)$ & & $1292.6 \pm 2198.4$ & $307.9(100.3,764.6)$ & \\
\hline \multirow[t]{2}{*}{ Mothballs } & No & 200 & $1684.5 \pm 4624.8$ & $0(0,494.4)$ & 0.87 & $709.5 \pm 1547.4$ & $210.7(25.3,525.7)$ & 0.55 \\
\hline & Yes & 4 & $1289.6 \pm 2579.2$ & $0(0,2579.2)$ & & $248.7 \pm 348.4$ & $115.2(50.1,447.3)$ & \\
\hline
\end{tabular}

Notes: The $P$ values were generated by multiple linear regression analysis. IQR, interquartile range; MBP, mono- $n$-butyl phthalate; MMP, monomethyl phthalate; $S D$, standard deviation. ${ }^{*} P<0.05$ (independent $t$ test).

(blood bags and administration of intravenous solutions) [8], outdoor and indoor dust [34], building materials such as vinyl floors and wall paper [35], and PVC flooring were not explored in this study. Moreover, only 2 phthalate metabolites were investigated and 1 method of urinary phthalate metabolite analysis was used in the present study.

We found lower urinary $\mathrm{Cr}$-adjusted MBP concentrations to be associated with advanced Tanner stage, but similar concentrations of MMP were found in advanced Tanner stage (Table 3). Urinary Cr-adjusted MBP concentration was higher in younger children than in older children. This finding was similar to that reported in a previous study, in which the level of DBP metabolites (the parent compound of MBP) was higher in the younger group than in the older group [38]. In younger children, hand-to-mouth behaviors and higher body surface area per weight were the factors that were found to cause greater 
Table 5. Literature review of studies of urinary phthalate metabolite levels

\begin{tabular}{|c|c|c|c|c|c|c|c|}
\hline Study & Population & Age (y) & Method & $\mathrm{MMP}(\mu \mathrm{g} / \mathrm{g} \mathrm{Cr})$ & DR & $\mathrm{MBP}(\mu \mathrm{g} / \mathrm{g} \mathrm{Cr})$ & DR \\
\hline \multirow[t]{7}{*}{ Guo Y [34] } & Chinese & $21-49$ & HPLC/MS & 9.7 & $50 \%$ & 69.5 & $>97 \%$ in \\
\hline & Indian & & & 5.8 & $>95 \%$ & 14.9 & all \\
\hline & Japanese & & & 11.1 & $>95 \%$ & 11.5 & \\
\hline & Korean & & & 2.7 & $50 \%$ & 19.8 & \\
\hline & Kuwaiti & & & Undetectable & $50 \%$ & 78.7 & \\
\hline & Malaysian & & & Undetectable & $33 \%$ & 15.1 & \\
\hline & Vietnamese & & & Undetectable & $50 \%$ & 14.1 & \\
\hline Guo C [31] & Chinese & $18-22$ & HPLC/MS & 12.2 & $99.1 \%$ & 74 & $100 \%$ \\
\hline Casas et al. [32] & Spain & 4 & HPLC/MS & Not done & Not done & 30.2 & Not done \\
\hline Silva et al. [33] & USA & $6-11$ & HPLC/MS & Not done & Not done & 38.9 & Not done \\
\hline Mouritsen et al. [36] & Denmark & $5.9-12.8$ & LC/MS & Not done & Not done & $\begin{array}{l}11.2 \mathrm{ng} / \mathrm{mL} \\
\text { (not corrected with } \mathrm{Cr} \text { ) }\end{array}$ & Not done \\
\hline Bertelsen et al. [37] & Norway & 10 & HPLC/MS & Not done & Not done & $\begin{array}{l}138.8 \mathrm{ng} / \mathrm{mL} \\
\text { (not corrected with } \mathrm{Cr} \text { ) }\end{array}$ & Not done \\
\hline Present study & Thailand & $2-18$ & HPLC & 0 & $28.5 \%$ & 252 & $88.6 \%$ \\
\hline
\end{tabular}

Notes: $\mathrm{Cr}$, creatinine; DR, detection rate; HPLC/MS, high-performance liquid chromatography/mass spectrometry; LC/MS, liquid chromatography/ mass spectrometry; NHANES, National Health and Nutrition Examination Survey.

exposure to phthalate sources in the environment. However, and after adjusting for sex (data not shown), urinary Cr-adjusted MBP level was negatively associated with Tanner stage.

Significant association was observed between urinary Cr-adjusted MMP level and exposure to floor cleaning liquid and paint, and between urinary Cr-adjusted MBP level and exposure to paint (Table 4). No previous study has reported these associations. One possible explanation is that there may be substantial differences in the formulations of floor cleaning liquid and paint used in Thailand. Conversely, certain phthalates that are known to be often present in various personal care products were not observed in the present study population. DBP (whose main metabolite is MBP) is often present in deodorants, perfumes [39], and food wrapping materials, and DMP (whose main metabolite is MMP) is often found in deodorants, shampoos, and hair styling formulations these were not found to be associated with phthalate metabolite concentrations. This may be the result of the small number of participants who use these products or to recall bias on the report prepared by parents describing their child's exposure history. No relationship was found between toothpaste use and phthalate metabolite concentrations, and $97.6 \%$ of participants reported using toothpaste. It may be that these products do not contain phthalates or that we did not measure the metabolites of the phthalate that is contained in the products.

Our results are not consistent with the increase in urinary phthalate concentrations that were observed when an increased number of products were used (data not shown), as was reported in other studies in adults [40] and infants [41].
The present study has some recognized limitations. First, although the size of the study population was relatively small, we were still able to demonstrate significant correlation between phthalates and some parameters. Second, only 2 low-molecularweight phthalate metabolites were measured in this study. If we had investigated additional phthalate metabolites, it is possible that other significant associations may have been identified. Third, Tanner staging was not performed by medical personnel. Fourth, it is possible that measurements of urine concentrations of phthalate metabolites may have been better if we had collected urine repeatedly. However, a study by Teitelbaum et al. [42] reported that a single spot urine sample sufficiently represented exposure over a 6 mo period to warrant its use as an exposure estimate in epidemiological studies. Finally, the children included in this study reside in metropolitan Bangkok - a major metropolis. As such, our findings may not be generalizable to all other areas of Thailand. Future studies in Thailand should include a larger sample size, more phthalate metabolites, and the use of a questionnaire with improved specificity for detecting the amount and frequency of product used.

\section{Conclusion}

This is the first study to investigate and report urinary phthalate metabolite levels in Thai children and adolescents. Rates of detection of MMP and MBP were lower in this study compared with the rates reported in other studies conducted in Asia, Europe, and the USA, but the urinary Cr-adjusted MBP levels 
in Thai children and adolescents were higher compared with the same in other studies. Exposure to paints and floor cleaning products was associated with increasing urinary $\mathrm{Cr}$-adjusted MMP levels. Early Tanner stage and exposure to paints were associated with higher urinary Cr-adjusted MBP levels.

Author contributions. NS and VS contributed substantially to the conception and design of the study. NS, CJ, and WN acquired, analyzed, and interpreted the data. All authors contributed to drafting and critically revising the manuscript, and take responsibility for the statements made in the published article.

Acknowledgments. The authors gratefully acknowledge Dr. Wichit Nosoongnoen of the Department of Pharmacy, Faculty of Pharmacy, Mahidol University - for assistance with HPLC and Dr. Chutima Jantarat of the School of Pharmacy, Walailak University, for assistance with measurement of urinary concentrations of phthalate metabolites. This study was supported by a grant (No. 2558-070) from the Ratchadaphiseksomphot Endowment Fund of the Faculty of Medicine, Chulalongkorn University, Bangkok, Thailand.

Conflict of interest. The authors have completed and submitted the International Committee of Medical Journal Editors Uniform Disclosure Form for Potential Conflicts of Interest. None of the authors disclose any conflict of interest.

\section{References}

[1] Diamanti-Kandarakis E, Bourguignon JP, Giudice LC, Hauser R, Prins GS, Soto AM, et al. Endocrine-disrupting chemicals: an Endocrine Society scientific statement. Endocr Rev. 2009; 30:293-342.

[2] Kim SH, Park MJ. Phthalate exposure and childhood obesity. Ann Pediatr Endocrinol Metab. 2014; 19:69-75.

[3] Watkins DJ, Eliot M, Sathyanarayana S, Calafat AM, Yolton K, Lanphear BP, et al. Variability and predictors of urinary concentrations of phthalate metabolites during early childhood. Environ Sci Technol. 2014; 48:8881-90.

[4] Fujii M, Shinohara N, Lim A, Otake T, Kumagai K, Yanagisawa Y. A study on emission of phthalate esters from plastic materials using a passive flux sampler. Atmos Environ. 2003; 37:5495-504.

[5] Elsisi AE, Carter DE, Sipes IG. Dermal absorption of phthalate diesters in rats. Fundam Appl Toxicol. 1989; 12:70-7.

[6] McKee RH, El-Hawari M, Stoltz M, Pallas F, Lington AW. Absorption, disposition and metabolism of di-isononyl phthalate (DINP) in F-344 rats. J Appl Toxicol. 2002; 22:293-302.

[7] Wormuth M, Scheringer M, Vollenweider M, Hungerbuhler K. What are the sources of exposure to eight frequently used phthalic acid esters in Europeans? Risk Anal. 2006; 26:803-24.

[8] Schettler T. Human exposure to phthalates via consumer products. J Androl. 2006; 29:134-9.
[9] Kim BN, Cho SC, Kim Y, Shin MS, Yoo HJ, Kim JW, et al. Phthalates exposure and attention-deficit/hyperactivity disorder in school-age children. Biol Psychiatry. 2009; 66:958-63.

[10] Frederiksen H, Skakkebaek NE, Andersson AM. Metabolism of phthalates in humans. Mol Nutr Food Res. 2007; 51:899-911.

[11] Braun JM, Sathyanarayana S, Hauser R. Phthalate exposure and children's health. Curr Opin Pediatr. 2013; 25:247-54.

[12] Swan SH, Main KM, Liu F, Stewart SL, Kruse RL, Calafat AM, et al. Decrease in anogenital distance among male infants with prenatal phthalate exposure. Environ Health Perspect. 2005; 113:1056-61.

[13] Suzuki Y, Yoshinaga J, Mizumoto Y, Serizawa S, Shiraishi H. Foetal exposure to phthalate esters and anogenital distance in male newborns. Int J Androl. 2012; 35:236-44.

[14] Foster PM. Disruption of reproductive development in male rat offspring following in utero exposure to phthalate esters. Int J Androl. 2006; 29:140-47; discussion 81-5.

[15] Wolff MS, Teitelbaum SL, Pinney SM, Windham G, Liao L, Biro F, et al. Investigation of relationships between urinary biomarkers of phytoestrogens, phthalates, and phenols and pubertal stages in girls. Environ Health Perspect. 2010; 118:1039-46.

[16] Grun F, Blumberg B. Environmental obesogens: organotins and endocrine disruption via nuclear receptor signaling. Endocrinology. 2006; 147 Suppl 6:S50-55.

[17] Cho SC, Bhang SY, Hong YC, Shin MS, Kim BN, Kim JW, et al. Relationship between environmental phthalate exposure and the intelligence of school-age children. Environ Health Perspect. 2010; 118:1027-32.

[18] Testa C, Nuti F, Hayek J, De Felice C, Chelli M, Rovero P, et al. Di-(2-ethylhexyl) phthalate and autism spectrum disorders. ASN Neuro. 2012; 4:223-9.

[19] Miodovnik A, Engel SM, Zhu C, Ye X, Soorya LV, Silva MJ, et al. Endocrine disruptors and childhood social impairment. Neurotoxicology. 2011; 32:261-7.

[20] Engel SM, Miodovnik A, Canfield RL, Zhu C, Silva MJ, Calafat AM, et al. Prenatal phthalate exposure is associated with childhood behavior and executive functioning. Environ Health Perspect. 2010; 118:565-71.

[21] Swan SH, Liu F, Hines M, Kruse RL, Wang C, Redmon JB, et al. Prenatal phthalate exposure and reduced masculine play in boys. Int J Androl. 2010; 33:259-69.

[22] Hurst CH, Waxman DJ. Activation of PPAR $\alpha$ and PPAR $\gamma$ by environmental phthalate monoesters. Toxicol Sci. 2003; 74:297-308.

[23] Just AC, Whyatt RM, Perzanowski MS, Calafat AM, Perera FP, Goldstein IF, et al. Prenatal exposure to butylbenzyl phthalate and early eczema in an urban cohort. Environ Health Perspect. 2012; 120:1475-80.

[24] Benayoun L, Letuve S, Druilhe A, Boczkowski J, Dombret MC, Mechighel P, et al. Regulation of peroxisome proliferator-activated receptor g expression in human asthmatic airways: relationship with proliferation, apoptosis, and airway remodeling. Am J Respir Crit Care Med. 2001; 164:1487-94.

[25] Hsu NY, Lee CC, Wang JY, Li YC, Chang HW, Chen CY, et al. Predicted risk of childhood allergy, asthma, and reported symptoms using measured phthalate exposure in dust and urine. Indoor Air. 2012; 22:186-99.

[26] Bornehag CG, Sundell J, Weschler CJ, Sigsgaard T, Lundgren B, Hasselgren $\mathrm{M}$, et al. The association between asthma and allergic symptoms in children and phthalates in house dust: a nested case-control study. Environ Health Perspect. 2004; 112:1393-7. 
[27] Kolarik B, Naydenov K, Larsson M, Bornehag CG, Sundell J. The association between phthalates in dust and allergic diseases among Bulgarian children. Environ Health Perspect. 2008; 116:98-103.

[28] Meeker JD, Hu H, Cantonwine DE, Lamadrid-Figueroa H, Calafat AM, Ettinger AS, et al. Urinary phthalate metabolites in relation to preterm birth in Mexico city. Environ Health Perspect. 2009; 117:1587-92.

[29] Whyatt RM, Adibi JJ, Calafat AM, Camann DE, Rauh V, Bhat HK, et al. Prenatal di(2-ethylhexyl)phthalate exposure and length of gestation among an inner-city cohort. Pediatrics. 2009; 124:e1213-20.

[30] Wu J, Ye Z, Li X, Wang X, Luo F, Sheng B, et al. Optimization of a $\mathrm{NH}_{4} \mathrm{PF}_{6}$-enhanced, non-organic solvent, dual microextraction method for determination of phthalate metabolites in urine by high performance liquid chromatography. J Chromatogr B. 2016; 1014:1-9.

[31] Gao CJ, Liu LY, Ma WL, Ren NQ, Guo Y, Zhu NZ, et al. Phthalate metabolites in urine of Chinese young adults: concentration, profile, exposure and cumulative risk assessment. Sci Total Environ. 2016; 543:19-27.

[32] Casas L, Fernández MF, Llop S, Guxens M, Ballester F, Olea N, et al. Urinary concentrations of phthalates and phenols in a population of Spanish pregnant women and children. Environ Int. 2011; 37:858-66.

[33] Silva MJ, Barr DB, Reidy JA, Malek NA, Hodge CC, Caudill SP, et al. Urinary levels of seven phthalate metabolites in the U.S. population from the National Health and Nutrition Examination Survey (NHANES) 1999-2000. Environ Health Perspect. 2004; 112:331-8.

[34] Guo Y, Kannan K. Comparative assessment of human exposure to phthalate esters from house dust in China and the United States. Environ Science Tech. 2011; 45:3788-794.
[35] Hauser R, Calafat AM. Phthalates and human health. Occup Environ Med. 2005; 62:806-18.

[36] Mouritsen A, Frederiksen H, Sørensen K, Aksglaede L, Hagen C, Skakkebaek NE, et al. Urinary phthalates from 168 girls and boys measured twice a year during a 5-year period: associations with adrenal androgen levels and puberty. J Clin Endocrinol Metab. 2013; 98:3755-64.

[37] Bertelsen RJ, Carlsen KC, Calafat AM, Hoppin JA, Håland G, Mowinckel P, et al. Urinary biomarkers for phthalates associated with asthma in Norwegian children. Environ Health Perspect. 2013; 121:251-6.

[38] Kim S, Kang S, Lee G, Lee S, Jo A, Kwak K, et al. Urinary phthalate metabolites among elementary school children of Korea: sources, risks, and their association with oxidative stress marker. Science Total Environ. 2014; 472:49-55.

[39] Romero-Franco M, Hernández-Ramírez RU, Calafat AM, Cebrián ME, Needham LL, Teitelbaum S, et al. Personal care product use and urinary levels of phthalate metabolites in Mexican women. Environ Int. 2011; 37:867-71.

[40] Duty SM, Ackerman RM, Calafat AM, Hauser R. Personal care product use predicts urinary concentrations of some phthalate monoesters. Environ Health Perspect. 2005; 113:1530-35.

[41] Sathyanarayana S, Karr CJ, Lozano P, Brown E, Calafat AM, Liu F, et al. Baby care products: possible sources of infant phthalate exposure. Pediatrics. 2008; 121:e260-68.

[42] Teitelbaum SL, Britton JA, Calafat AM, Ye X, Silva MJ, Reidy JA, et al. Temporal variability in urinary concentrations of phthalate metabolites, phytoestrogens and phenols among minority children in the United States. Environ Res. 2008; 106:257-69. 
